\title{
Analysis of Adverse Selection and Moral Hazard in the Health Insurance Market of Iran
}

\author{
GholamReza Keshavarz Haddad and Mahdieh Zomorrodi Anbaji \\ Graduate School of Management and Economics, Sharif University of Technology, Azadi avenue, Tehran \\ $11365 / 8639$, Iran. \\ E-mails: G.K.Haddad@Sharif.edu; Mahdieh_Zomorrodi@alum.sharif.edu
}

This paper aims to estimate a demand model for health insurance and medical care in Iran, in the presence of heterogeneous and latent health status of individuals; moreover it tests the asymmetry of information in the health insurance market. Our data set have been taken from the Households' expenditures survey (2006) of Iran. Parameters of the model are estimated by the Generalized Method of Moments (GMM) and the presence of asymmetric information (adverse selection and moral hazard) is tested by a non-parametric econometric method. The analytical model is specified under minimal assumptions on the selection process of different insurance categories and the statistical distribution of individual's latent health status. The findings confirm the presence of adverse selection hypothesis in personally purchased health insurance and moral hazard in all health insurance categories.

The Geneva Papers (2010) 35, 581-599. doi:10.1057/gpp.2010.20

Keywords: adverse selection; moral hazard; health insurance; Iran

\section{Introduction}

Price trends over the last 10 years (1997-2006) indicate that the growth of price index for medical care constantly exceeds the consumer's price index (CPI) in Iran. The growth of CPI was 14 per cent in 2006, whereas that of medical care's costs amounted to 19 per cent. A necessary consequence of this significant inflation in medical care price is pushing more than 2 per cent of families under poverty line every year. On the other hand, it results in increasing costs of insurance companies and more pressures on their financial resources. One commonly suggested cause for these higher price inflations in medical care services is increased demand for health care and medical utilisation, which seems to be due to asymmetric information of the individuals' latent health status between insured and insurer. Since insured people usually do not pay the total amount of medical costs, they do not have strong incentives to economise their medical utilisations. This over-utilisation would cause more inflation in medical and health care prices through the increased demand for the services (Figure 1).

The main purpose of the paper is to test asymmetry of information in the health insurance market of Iran. To achieve the goal, first a demand equation for medical care is specified, with minimal statistical assumptions, allowing the presence of adverse selection and moral hazard. Then, parameters of the structural model are estimated by a semi-parametric approach. Specifically, the health status of individuals, which is used in non-parametric test of adverse selection and moral hazard, are obtained 


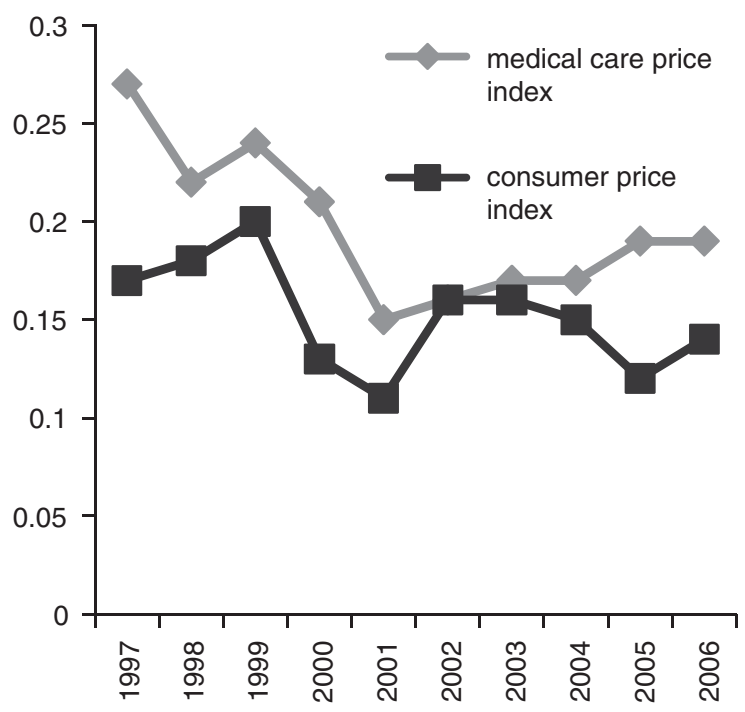

Figure 1. CPI and Medical Care Price Index during 1997-2006, Iran.

Source: Central Bank of Islamic Repulic of Iran; www.cbi.ir.

non-parametrically. Also the attitude of individuals towards risk in consumption of usual and medical goods will be examined.

The health insurance system in Iran consists of two major public insurance services providers and by law, wage earners of private and public sectors have to be covered by either of them. But about 20 commercial insurance companies are supplying the services as supplementary health insurance and the insured can arbitrarily choose to buy their policies. Because of low payments of public insurers, usually private hospitals and specialist physicians do not provide medical services for their insured, but they provide the medical services for private insurance policy-holders. There are no recorded and reliable data on the premiums and reimbursements of private insurances in the households' expenditure survey. Therefore we confine the scope of the research to the medicine and paraclinical services, which annually make up 60 per cent of reimbursements of the two major public medical insurance service providers: Social Security Organization (covers 27 million people) and Medical Services Insurance Organization (covers 38 million people), and the survey reports well defined and accurate data for the out-of-pocket money of the services. Although these organisations are managed by the government, they are financed by insureds, employers and partially by the government. Table 1 shows the shares of insured, employer and government in insurance premium of insureds.

The total amount of insurance premium of wage earners (office workers and employerprovided) who are insured by either of the organisations equals 30 per cent of their monthly salary which are paid according to the Table 1 , but the personally insured ${ }^{1}$ have

\footnotetext{
${ }^{1}$ Personally insured is a person who is not a wage earner, but he/she may either work in his/her own business or is unemployed and pays the insurance premium entirely.
} 
Table 1 Shares of insured, employer and government in insurance premiums

\begin{tabular}{lccccc}
\hline & \multicolumn{2}{c}{ Medical Services Insurance Organization } & & & \multicolumn{2}{c}{${\text { Social Security } \text { Organization }^{\mathrm{b}}}^{$\cline { 2 - 3 } \cline { 5 - 6 }$}$} & Office workers & Personally insured & & Employer provided & Self-employed \\
\hline Insured & 30 & 100 & 0 & 23 & 90 \\
Government & 70 & - & & 67 & 10 \\
Employer & - & - & & 67 & - \\
\hline
\end{tabular}

${ }^{a}$ www.msio.org.ir.

bwww.tamin.org.ir.

All figures are in per cent.

to pay a fixed amount of money as a premium which may change with time. Although both of the public insurance organisations pay 70 per cent of unlimited costs of the medicine and paraclinical services, they do not cover majority of clinical and surgical services. Furthermore, many private insurance companies provide the medical insurance services with variable ranges of coverage, which are determined according to the insurance contracts.

The paper uses an explicit demand function for medicine and paraclinical services and estimates structural parameters of consumer's utility function by GMM to overcome the likely endogeneity of explanatory variables in the nonlinear first order condition of utility maximisation problem. In the Iranian insurance market, the reimbursement function does not follow the assumption of Bajari's (2005) which use the Nadaraya-Watson kernel estimator to recover the reimbursement schedule conditional on the insurance choice, non-parametrically from the data. Instead, the schedule is determined by labour law as a predetermined identity, where the out-of-pocket share of insured is 0.3 of total medicine and paraclinical costs.

The rest of the paper is organised as follows. The following section reviews theoretical and empirical background. Our analytical framework, which consists of a risk-averse utility function with a composite good of non-health and health care, is presented in the subsequent section. The next following section explains the data set. Our estimation, hypothesis testing and results are presented in the penultimate section. The final section summarises and makes concluding remarks.

\section{Theoretical and empirical background}

The asymmetric information theory anticipates a positive association between high coverage policy selection and higher risks of policy-holders. Under adverse selection, high-risk policy-holders buy more generous insurance, while under moral hazard generously insured policy-holders make less of an effort to prevent illness (ex-ante moral hazard), furthermore they use more and expensive medical care (ex-post moral hazard). Consequently, they are considered high risk for an 
insurance company. Theoretical literature on information asymmetry can be categorised in four streams:

1. Adverse selection theory was postulated by Akerlof, ${ }^{2}$ in the health insurance market for older people (older than 65 years). Rothschild and Stiglitz ${ }^{3}$ argued that, in an imperfect information market, competitive equilibrium might not exist. They identified two kinds of equilibriums, pooling equilibrium, in which all agents are offered the same contract, and separating one in which different types of contracts are offered to each group of agents. Wilson (1980) also described risk-pooling as a cross-subsidisation of high-risk agent by low risks. Cave ${ }^{4}$ suggests crosssubsidisation from a moderate insurance plan to a generous one, as a procedure to achieve a separating equilibria. Feldman and Dowd, ${ }^{5}$ and Cutler and Reber $^{6}$ independently proved that in a dynamic process of re-contracting in the presence of adverse selection, more generous plans would be omitted. Insurers tend to attract healthier agents, so they limit their offered insurance coverage to prevent the occurrence of adverse selection problems. They named this removing process "death spiral". Also Cutler and Zeckhauser" and more recently Pauly examined methods which may prevent the problem. Their result suggests offering separating contracts, cross-subsidising and preventing insureds from choosing limited coverage plans. Several empirical studies on the problem have been conducted which have been reached to consistent results. Cameron (1988), Browne, ${ }^{9}$ Doerpinghaus, ${ }^{10}$ Gilleskie $^{11}$ and Khwaja (2002) are among many others. Despite the presence of a significant fraction of uninsured people in the U.S. and considerable differences in private employer-provided health insurance, Cardon and Hendel ${ }^{12}$ do not confirm the presence of adverse selection in the health insurance market of the U.S. Buchmueller ${ }^{13}$ examines the issue of adverse selection in the market for private health insurance in Australia. The paper confirms the effects of adverse selection due to insurance reform (1999s) on the insurance premiums. The results show that the reform induced a greater number of younger consumers into the market, and have lowered the average premiums.

2. Ex-ante moral hazard theory asserts that, although health status of agents in the future is uncertain and probabilistic, they can affect the probability value. Zweifel and Breyer ${ }^{13}$ specify a model which optimises the level of individual efforts to prevent from sickness. They come to the conclusion that, in the optimal condition,

\footnotetext{
${ }^{2}$ Akerlof (1970).

${ }^{3}$ Rothschild and Stiglitz (1976).

${ }^{4}$ Cave (1985).

${ }^{5}$ Feldman and Dowd (1991).

${ }^{6}$ Cutler and Reber (1998).

${ }^{7}$ Cutler and Zeckhauser (2000).

${ }^{8}$ Pauly (2006).

${ }^{9}$ Browne (1992).

${ }^{10}$ Doerpinghaus (1993).

11 Gilleskie (1998).

12 Cardon and Hendel (2001).

${ }^{13}$ Buchmueller (2008).
} 
individuals balance between yielded utility of preventive medical care-due to decreased probability of sickness - and the disutility cost of preventive effort because of lost wage. Kenkel ${ }^{14}$ argued that preventive medical care is optional as it does not have uncertain nature, and it is not insurable. A few empirical researches were conducted in this area. For instance, Roddy et al., ${ }^{15}$ Keeler and Rolph ${ }^{16}$ and Cherkin et al. ${ }^{17}$ have investigated the impacts of cost-sharing in health insurance schedules on the demand for preventive care. They came to the conclusion that a higher level of coverage leads to an increase in preventive care. Courbage and de Coulon ${ }^{18}$ tested the presence of ex-ante moral hazard in the U.K. Although they did not find any evidence of ex-ante moral hazard, their results suggest that in the U.K. more insurance coverage may lead to more prevention. Using data from the U.S. Panel Study of Income Dynamics (1999-2003), Stanciole ${ }^{19}$ shows that health insurance provides significant incentive effects on lifestyle choice, increasing the propensity to heavy smoking, lack of exercise and obesity and decreasing the propensity to heavy drinking.

3. The issue of ex-post moral hazard refers to the action of individuals in buying services, where the entire or a fraction of its price is paid by others. This concept was introduced by Arrow ${ }^{20}$ in health insurance markets. Pauly, ${ }^{21}$ Zeckhauser, ${ }^{22}$ Spence and Zeckhauser (1971), Blomqvist (1997), Cutler and Zeckhauser ${ }^{7}$ and Goldman and Philipson (2007) derived optimal reimbursement policy in the presence of ex-post moral hazard. The idea beyond all of these studies is an expected utility maximisation subject to zero profit of insurance company. Several empirical studies such as Heaney and Riedel, ${ }^{23}$ Scitovsky and Snyder, ${ }^{24}$ Rosett and Huang, ${ }^{25}$ Phelps and Newhouse ${ }^{26}$ have carried out the ex-post moral hazard problem.

4. Bajari et al. ${ }^{27}$ is the only paper which examined the presence of adverse selection and moral hazard simultaneously. They used a sample of men and women born between 1931 and 1941 and their families Health and Retirement Study (HRS). The authors use a Kolmogorov-Smirnov test statistic to see if the uninsured are truly different than the insured in the U.S. They found that the health distributions between people who are not insured is statistically significantly different from people in all the other insurance categories, including employer provided insurance,

\footnotetext{
14 Kenkel (2000).

15 Roddy et al. (1986).

${ }^{16}$ Keeler and Rolph (1988).

${ }^{17}$ Cherkin et al. (1990).

${ }^{18}$ Courbage and de Coulon (2004).

19 Stanciole (2008).

${ }^{20}$ Arrow (1963).

${ }^{21}$ Pauly (1968).

${ }^{22}$ Zeckhauser (1970).

${ }^{23}$ Heaney and Riedel (1970).

${ }^{24}$ Scitovsky and Snyder (1972).

${ }^{25}$ Rosett and Huang (1973).

${ }^{26}$ Phelps and Newhouse (1974).

${ }^{27}$ Bajari et al. (2006).
} 
insurance of self-employed, personal insurance and Medicare. Similarly, with only two exceptions, they also find evidence against the null hypothesis of no adverse selection in the pair-wise comparison among different insurance categories. The two exceptions are: first, there is no significant difference in the unobserved health distributions between individuals in the insurance category of employer-provided insurance and self-employed; second, they find no difference between those who have personal insurance and individuals in Medicare. Furthermore, Bajari et al. ${ }^{28}$ propose a two-step semi-parametric estimation strategy that builds on the work of identification and estimation of auction models. They find significant evidence of moral hazard and adverse selection in U.S. health insurance markets.

The above empirical evidences show that demand for preventive medical services is decreasing function of out-of-pocket money, and findings show that demand for the preventive services is more elastic than that of other medical services. Also empirical literature confirms that demand for medical utilisations has a reverse relationship with the out-of-pocket rate, although the magnitude differs with the demographical, geographical and socioeconomic status of individuals.

\section{The analytical framework}

Our theoretical and consequently empirical models are based on the Cutler and Zeckhauser ${ }^{7}$ and Bajari et al. ${ }^{27}$ At first, we specify a consumer's endogenous demand for medical care utilisation in the presence of adverse selection and moral hazard, which allows unobservable heterogeneity in the distribution of the health status of individuals. Following Spence and Zeckhauser (1971), Blomqvist (1997) and Bajari et al. ${ }^{27}$ we specify representative consumer's utility as a function of their wealth $(w)$, nature's action $(\theta)$ which reflects external shocks on their health status, and the choice variable of individuals $(m)$, which can be treated as the invested amount of money on their health. We consider $(m)$ as the total expenditures on medicine and paraclinical services.

Let us take household derives utility from $(m-\theta)$ and $c$ by $U(c, m-\theta ; \gamma)$, where $m$ is expenditures on medicine and paraclinical services, $\theta$ is latent health status of individual, $c$ is composite good which contains the value of all other commodities and finally the risk aversion parameter vector is $\gamma$.

Since both $(m)$ and $\theta$ are money-metric, their difference is allowed directly to be included in the utility function.

$$
\begin{array}{cl}
\operatorname{Max}_{m} & U(c, m-\theta ; \gamma)=\left(\frac{1}{1-\gamma_{1}}\right) c^{1-\gamma_{1}}+\left(\frac{\gamma_{2}}{1-\gamma_{3}}\right)(m-\theta)^{1-\gamma_{3}} \\
& \text { subject to } c=y-p-z(m)
\end{array}
$$

Where $y$ is total expenditure of family, $p$ is insurance premium, $z(m)$ is out-ofpocket money for medical utilisation (medicine and paraclinical services) and the

\footnotetext{
${ }^{28}$ Bajari et al. (2009).
} 
objective function is maximised with respect to $m$. Therefore their reimbursement is $(m-z)$ and $m$ is the total amount of medical expenditures (medicine and paraclinical services). It is assumed that the insurer sets reimbursement plan $(m-z(m))$ prior to realisation of the individual's health shocks. The assumption that $z$ is determined only by $m$ is the origin of moral hazard problems. Given the value of $\theta$, a consumer chooses $m(\theta)$ to maximise his/her utility. To avoid the computational complications, we assume $U_{c, m}=0$. This assumption is not too far from stylised facts; there are several empirical studies which confirm the separability between medicine use and utilisation of other medical services such as inpatient, outpatient and ambulatory services. For example Stuart (2004), Briesacher (2005), Shang ${ }^{29}$ and Khan (2007) have among others, tested significance of this separability in the short run. Furthermore we assume that $m$ is a non-decreasing function of $\theta$. First order conditions associated with the optimal $\theta$ is

$$
U_{m}(c, m-\theta ; \gamma)-U_{c}(c, m-\theta ; \gamma)\left[z^{\prime}(m)\right]=0
$$

The (2) provides the standard rule for MRS of medical utilisation for composite good. It asserts that marginal utility of medical care on the marginal utility of composite good must be equal to their relative prices. This optimal condition relates the latent health status of individual to the observable total medical expenditure of $m$. It provides that

$$
\gamma_{2}(m-\theta)^{-\gamma_{3}}=c^{-\gamma_{1}}\left(z^{\prime}(m)\right)
$$

where

$$
\hat{z}^{\prime}(m ; d)=\left\{\begin{array}{lll}
1, & \text { if } \quad d=1 \\
0.3, & \text { if } \quad d=0
\end{array}\right.
$$

is the out-of-pocket schedule which is determined exogenously by laws and regulations. We will base our analytical model on equation (3), which is a nonlinear regression model with likely endogenous explanatory variables.

\section{Data description}

In the health insurance market of Iran, the majority of insureds have no choice in selecting their desired insurance plan. In other words, depending on their jobs, individuals have to choose one of (1) employer provided, (2) self-employed and (3) personal insurance, which are provided by Social Security Organization and Medical Services Insurance Organization or (4) uninsured, in which 66 per cent of individuals in the sample are uninsured, 13 per cent are office workers, 13 per cent are employer provided, 3 per cent are personally purchased and 5 per cent out of 30,902 are self-employed individuals. Thus an individual subject to the obligatory insurance and his/her realised health status $\theta_{i}$ uses medical services. The Households'

\footnotetext{
${ }^{29}$ Shang (2005).
} 
Expenditure Survey is conducted annually with a sample size of 30,902 for rural and urban households by the Statistical Center of Iran by clustering method and consists of four sections: (1) socioeconomic characteristics, (2) dwelling characteristics, (3) monthly food and non-food expenditures of households and (4) households' monthly wage and non-wage incomes. We confine the scope of our study to the test and analysis of asymmetric information in the preclinical services (medicines, radiological and medical lab) utilisation, because the public insurance organisations cover almost all the services and pay the 70 per cent of their expenditures; therefore only 0.3 of the expenditures are reported in the survey as monthly out-of-pocket money in the Households' Expenditure Survey. The survey does not clearly categorise physicians, dental, mental, surgery and hospital expenditures, which are paid to private and public medical service providers. These service providers (hospitals, physicians and private clinics) charge patients either directly or through their private insurance policy, although public hospitals and their physicians provide medical services for the insured individuals and charge solely 30 per cent of the amount. The data set report sum of the expenditures irrespective of the services are paid directly, by private insurances or the public insurance organisations. Therefore, to achieve a reliable inference, we model the public insurance fully covered services. The variables used in our analysis and it corresponding summary statistic are described in Table 2.

Total expenditures on medicine and preclinical services are calculated by multiplying out-of-pocket money for medicine and preclinical services by (10/3) for insured and by one for uninsured. Monthly total expenditure is defined as the average of 12-month expenditure of the households. Moreover, we have used social characteristics (including age, gender, education, ... ) of families which are reported in the survey for each household. Out-of-pocket rate for insured individuals, in both Social Security Organization and Medical Services Insurance Organization is 0.3 of $m$ (total expenditure for medicine and paraclinical cares) and for those of uninsured is 1. So we define:

$$
\hat{z}(m ; d)=\left\{\begin{array}{lll}
m, & \text { if } \quad d=1 \\
0.3 m, & \text { if } \quad d=0
\end{array}\right.
$$

as the out-of-pocket expenditure for both insured and uninsured individuals. Where $d=1$ stands for individuals who are not insured and $d=0$ otherwise. Average age (59 years old) and out-of-pocket money US\$12.51 for personally insured is the greatest among all the groups and those of self-employed is of the second rank; it shows that they might be rather risky for the insurers' portfolio. Insurance contracts not only cover the household's head, but also cover all family members of office workers, and employee and employer. Family size averages of those households are greater than 4.4 people; therefore they impose more costs on the financial resources of insurers. On the other side if we consider medical services as normal goods, holding all other factors fixed, office workers will utilise the services more than other groups. 
Table 2 Description of variables and descriptive statistic

\begin{tabular}{|c|c|c|c|c|c|}
\hline Variable & Variable description & Mean & Std. Dev. & Min & $\operatorname{Max}$ \\
\hline \multicolumn{6}{|c|}{ Total expenditures on medicine and paraclinical services } \\
\hline \multirow[t]{6}{*}{$m$} & Uninsured & 7.65 & 23.22 & 0 & $1,626.54$ \\
\hline & Office workers & 33.16 & 114.23 & 0 & $4,463.97$ \\
\hline & Employee and employer & 29.54 & 81.25 & 0 & $2,034.98$ \\
\hline & Personally insured & 41.73 & 100.45 & 0 & $1,373.53$ \\
\hline & Self-employed & 37.38 & 96.85 & 0 & $1,355.45$ \\
\hline & Total expenditure of househ & & & & \\
\hline \multirow[t]{6}{*}{$Y$} & Uninsured & 367.63 & 365.97 & 3.25 & $6,794.03$ \\
\hline & Office workers & 787.15 & 579.46 & 8.51 & $8,295.84$ \\
\hline & Employee and employer & 567.14 & 434.57 & 78.28 & $5,231.51$ \\
\hline & Personally insured & 589.81 & 533.27 & 28.38 & $5,707.22$ \\
\hline & Self-Employed & 607.19 & 583.09 & 12.23 & $10,034.72$ \\
\hline & Out-of-pocket money for me & ne and parc & ical services & & \\
\hline \multirow[t]{6}{*}{$z(m)$} & Uninsured & 7.65 & 23.22 & 0 & 1626.55 \\
\hline & Office Workers & 9.95 & 34.27 & 0 & 1339.19 \\
\hline & Employee and employer & 8.86 & 24.38 & 0 & 610.49 \\
\hline & Personally insured & 12.52 & 30.14 & 0 & 412.06 \\
\hline & Self-employed & 11.21 & 29.05 & 0 & 406.64 \\
\hline & Insurance premium & & & & \\
\hline \multirow[t]{6}{*}{$p$} & Uninsured & 0 & 0 & 0 & 0 \\
\hline & Office Workers & 6.71 & 6.22 & 0.003 & 117.99 \\
\hline & Employee and employer & 7.06 & 6.92 & 0.05 & 82.23 \\
\hline & Personally insured & 4.79 & 5.69 & 0.14 & 64.85 \\
\hline & Self-employed & 11.39 & 14.84206 & 0.216873 & 228.04 \\
\hline & Age of household's head & & & & \\
\hline \multirow[t]{6}{*}{ Age } & Uninsured & 48.67 & 16.33 & 16 & 99 \\
\hline & Office workers & 44.58 & 11.46 & 20 & 95 \\
\hline & Employee and employer & 43.59 & 13.26 & 18 & 99 \\
\hline & Personally insured & 59.26 & 13.01 & 22 & 93 \\
\hline & Self-employed & 54.42 & 14.42 & 21 & 99 \\
\hline & Household size & & & & \\
\hline \multirow[t]{6}{*}{ Hsize } & Uninsured & 4.44 & 2.16 & 1 & 12 \\
\hline & Office workers & 4.46 & 1.65 & 1 & 16 \\
\hline & Employee and employer & 4.45 & 1.74 & 1 & 12 \\
\hline & Personally insured & 3.46 & 1.67 & 1 & 11 \\
\hline & Self-employed & 3.78 & 1.72 & 1 & 14 \\
\hline & Income & & & & \\
\hline \multirow[t]{5}{*}{ Inc } & Uninsured & 343.054 & 429.94 & 13.01 & $18,651.05$ \\
\hline & Office workers & 743.2711 & 509.17 & 74.84 & $12,795.49$ \\
\hline & Employee and employer & 542.6902 & 551.89 & 58.74 & $27,109.09$ \\
\hline & Personally insured & 550.2792 & 454.15 & 55.21 & $8,148.863$ \\
\hline & Self-employed & 601.1693 & 730.26 & 45.99 & $18,434.18$ \\
\hline
\end{tabular}

$Y, M, P, z(m), H-G$ and $E X P E N$ are measured in Dollars; Age is measured in year and Hsize in people; $p$ are measured for insured individuals. Number of Observation for uninsured is 20,375; for office worker is 3,935; for Employee and employer is 4,002; for Personally insured is 1,063 and for self-employed is 1,527.

The original figures were in Rails, and we changed Rails to US\$, $\$ 1=9,222$ Rials. 


\section{Estimation methodology}

With making use of households' budget survey data set for Iran (2006), this section presents the risk aversion parameters estimation of the first order condition (3). Furthermore, we are interested in deriving the individual's health shocks $\theta_{i}$ to test the presence of adverse selection and the elasticity of medical expenditure with respect to a local change in the rate of reimbursement of medical expenditures to test the presence of moral hazard. To do so, we should take two steps of parameter estimation by (GMM) and conducting a non-parametric equality test of empirical distributions (Kolmogorov-Smirnov test), respectively.

Unlike the Maximum Likelihood Estimation (MLE) the GMM does not require any a priori assumption on the probability distribution on the disturbance term of regression (3), which is derived from theoretical first-order condition of a utility maximisation problem. GMM estimators are consistent, efficient and asymptotically normal, even when the explanatory variables are endogenous. ${ }^{30}$ Our identification strategy only depends on the correct specification of the consumer utility function and the validity of the economic hypothesis of utility maximisation, but not on the statistical hypothesis regarding the reimbursement schedule and the distribution of health status $\theta_{i}$. The parameters of (3) are estimated by GMM in which exogenous vector of $\mathrm{x}_{i}$ is defined as instrumental variables. The assumption that the instruments $\mathrm{x}_{i}$ are exogenous can be expressed as $E\left(\mathbf{x}_{i}^{\prime} \theta_{i}\right)=0$. The $L$ instruments give us as set of $L$ moments, $\mathrm{g}_{i}(\gamma)=\mathrm{x}_{i}^{\prime} \theta_{i}=\mathrm{x}_{i}^{\prime} \varphi\left(m_{i}, p_{i}, \mathrm{y}_{i}, \hat{z}\left(m_{i} ; d_{i}\right), \gamma\right)$. Where $\mathrm{g}_{i}(\gamma)$ is $L \times 1$. Exogeneity of the instruments means that there are $L$ moment conditions, that will be satisfied at the true value of $K$ parameters $\gamma=\gamma_{0} ; E\left(\mathbf{g}_{i}(\gamma)\right)=0$. Each of the $L$ sample moment equations corresponds to a sample moment, and we write these $L$ sample moments as:

$$
\bar{g}(\gamma)=1 / n \sum_{i=1}^{n} g_{i}(\gamma)=1 / n \sum_{i=1}^{n} x_{i}^{\prime} \varphi\left(m_{i}, p_{i}, y_{i}, \hat{z}\left(m_{i} ; d_{i}\right), \gamma\right)
$$

The intuition behind GMM is to choose an estimator for $\gamma$, that sets these $L$ sample moments as close to zero as possible. If the equation to be estimated is exactly identified, so that $L=K$, then we have as many equations - the $L$ moment conditionsas we do unknowns - the $K$ coefficients in $\gamma$. In this case, it is possible to find a $\hat{\gamma}$ that solves $\bar{g}(\gamma)=\mathbf{0}$, and this GMM estimator, in fact, is the IV estimator. If the equation is overidentified, however, so that $L>K$, then we have more equations than we do unknowns, and in general it will not be possible to find a $\hat{\gamma}$ that will set all $L$ sample moment conditions to exactly zero. In this case, we take a $L \times L$ weighting matrix W and use it to construct a quadratic form in the moment conditions. This gives us the GMM objective function, $Q(\hat{\gamma})=n \bar{g}(\gamma)^{\prime} \mathrm{W} \bar{g}(\gamma)$. A GMM estimator for $\gamma$ is the $\hat{\gamma}$ that minimises $Q(\hat{\gamma})$. Where $\mathrm{W}=\left[(1 / n) E\left(\mathrm{X}^{\prime} \theta \theta^{\prime} \mathrm{X}\right)\right], \mathrm{X}$ and $\theta$ are matrix and vector forms of instrumental variables and unobservable variable of individuals' health status. A test of validity of the overidentifying restrictions can be made by comparing the value of the objective function with its expected value under the null hypothesis that the

\footnotetext{
${ }^{30}$ Newey and McFadden (1994).
} 
restrictions are valid. Under the null hypothesis that the overidentifying restrictions are true, the test statistic:

$$
n Q_{n}(\hat{\gamma}) \stackrel{D}{\rightarrow} \chi_{L-K}^{2}
$$

where $Q_{n}(\hat{\gamma})$ is the objective function that is optimised to find the GMM estimators. Clearly, a proper instrument set should be independent of $\theta_{i}$, but strongly can explain insurance demand. We assume that elements of $\mathbf{x}_{i}$ reflect variations in costs of providing insurance such as age, education, household size, income, constant term and age squared, and independent of unobservable health status of individual.

Although $\theta_{i}$ is unobservable, it can be uniquely calculated from (3). By substitution of $\hat{z}(m ; d)$ in (5), the explicit functional form of $\theta_{i}$ is derived as

$$
\hat{\theta}_{i}=\varphi\left(m_{i}, p_{i}, y_{i}, \hat{z}\left(m_{i} ; d_{i}\right), \gamma\right)
$$

More specifically, making use of Equation 1 , for $(m) \geqslant 0$ we have

$$
\varphi\left(m_{i}, p_{i}, \hat{z}\left(m_{i} ; d_{i}\right), \hat{\gamma}\right)=m_{i}-\left[\left(1 / \gamma_{2}\right)\left(y_{i}-p_{i}-\hat{z}_{i}\left(m_{i} ; d_{i}\right)\right)^{-\gamma_{1}}\left(\hat{z}^{\prime}\left(m_{i} ; d_{i}\right)\right)\right]^{-1 / \gamma_{3}}
$$

The intuition behind $z^{\prime}(m) \geqslant 0$ is, while medical care utilisation raises, out-of-pocket expenditure should increase as well. Components of exogenous vector are income, household size and intercept term, which are of the most association with explanatory variables of model (6) and on the other hand the least correlation with $\theta_{i}$. We also tried other instrument such as age, age squared, education, gender and being rural or urban, but results were not satisfactory.

Table A1 reports the estimation results. All of estimated parameters are significant at 0.05 significance level and the null hypothesis of overidentifying restrictions is not rejected at 1 per cent significance level. Risk aversion parameter of consumption composite good is $\hat{\gamma}_{1}=0.27$, while that of medicine and paraclinical services is $\hat{\gamma}_{3}=0.71$. Consequently on average, individuals are more risk-averse in health care, in comparison with other goods. Also the weight of medical utilisation in the utility function amounts to $\hat{\gamma}_{2}=39$, which indicates the importance of medical care and health status in the individuals' preferences. Estimated value of $\gamma_{1}$ and $\gamma_{3}$ do not differ substantially from those of Bajari et al., ${ }^{27}$ which are 0.64 , and 1.39 respectively; and economically both sets of estimated values reveal that individuals are more risk-averse with respect to health care than composite consumption goods. Although our calculated value for $\gamma_{2}$ is noticeably greater than that of 5.4 Bajari et al., ${ }^{27}$ similarly it shows the importance of health care consumption in two data sets. Calculated Arrow-Pratt absolute risk aversion coefficient $r_{A}(m)=-u_{m}{ }^{\prime \prime} / u_{m}{ }^{\prime}=\gamma_{3} /(m-\theta)$ shows a decreasing reaction against individual's income. That is, while the income of individuals increases, $r_{A}(m)$ decreases smoothly. Table A2 reports the summary of these findings.

Kolmogorov-Smirnov test is applied to test the presence the both kinds of information asymmetry. Let $x_{1}, \ldots, x_{m}$ be a random sample from a population with the distribution function of $F(x)$, and empirical sample distribution of $F_{m}(x)$. Also we consider $y_{1}, \ldots, y_{n}$ as a random sample with $G(x)$ and $G_{n}(x)$ as its population and 
empirical sample distribution, respectively. Smironov (1939) suggested the $D_{m, n}=$ $\sup _{x}\left|F_{m}(x)-G_{n}(x)\right|$ statistic to test the equality of the empirical distributions. The null distribution of the statistic is derived under the null hypothesis that the samples are drawn from the same distribution. The test statistic is used to test the equality of health status $\theta_{i}$ and demand price elasticities' probability distributions of individuals in different categories pair wisely.

\section{Adverse selection test}

In the second step of our assessment, we calculate $\theta_{i}$ from equation (6) for all individuals. We also obtain conditional distribution of $\theta_{i}$ in the insurance categories of: (1) uninsured people, (2) office workers' insurance provided by Medical Services Insurance Organization, (3) employer provided insurance by Social Security Organization, (4) personal insurance by Medical Services Insurance Organization, (5) self-employed insurance by Social Security Organization.

The equality of conditional distributions is tested non-parametrically by Kolmogorov-Smirnov test statistic. The null hypothesis implies that conditional distributions of health status of individuals are identical among all possible pairs of the insurance categories. P-value of tests together with Kolmogorov-Smirnov statistics are reported in Table A3, which significantly rejects the distributions equality of uninsured with other insurance categories. Also, the test failed to reject the equality of health status distributions of the self-employed and personally insured. This implies the absence of any significant difference between the health statuses of these groups at 0.05 significance level. Summary statistics of health status categories are figured out in Table A4. This result together with reported statistics in Table A4 indicate that health status of office workers with average of -US\$7.49; employer and employee with US\$6.30 and self-employed with US\$1.352 are considerably better than uninsured whose average health shock is US\$2.27. Therefore, the presence of adverse selection hypothesis is rejected for these insurance categories. This result is consistent with reality, because the first two insurance categories are obligatory and adverse selection cannot occur in the market for the categories. In the third category, there are two preconditions that must be held: maximum age for acceptance in this insurance category is 55 years and clients must have physician approval health checks. Consequently, this kind of insurance successfully prevents adverse selection occurrence. On the other hand, the average health shock of personally insured individuals is US\$5.85, which shows the worse health status among the insurance categories, together with Kolmogorov-Smirnov statistic, the presence of adverse selection in this group is confirmed. This finding stems from the optional nature of this type of insurance, which is a one-year contract, and usually individuals who buy this insurance have emergency need to medical care and have encountered positive health shocks. The inequality of health status distributions with that of the uninsured is similar to the findings in Bajari (2005). Also, they show that the health status of Personally Purchased and Medicare are worse than uninsured. Although Iran does not have Medicare insurance plan, our findings about the presence of adverse selection of personally purchased, in which mean of age is older than 59 years, are similar to Bajari (2005). 
The unobservable health status of $\theta$ is a money-metric random variable, which takes values in $(-\infty,+\infty)$. A positive value implies a health shock, which imposes a cost burden to the individual and in turn on the insurer. However, the negative shocks such as stopping smoking and drinking, and doing regular physical practices, shows reductions in the medical care costs.

\section{Moral hazard test}

Bajari et $a .^{27}$ introduced the elasticity of medical expenditure with respect to a local change in the rate of reimbursement of medical expenditures, as a measure of moral hazard. Taking an implicit derivative from (3) and substituting $z^{\prime}(m)$ from (4) will result in

$$
\text { elasticity }=\frac{\partial m_{i}}{\partial z^{\prime}\left(m_{i}\right)} \times \frac{z^{\prime}\left(m_{i}\right)}{m_{i}}=\frac{-\gamma_{1} c_{i}^{-\gamma_{1}-1} m_{i} z^{\prime}\left(m_{i}\right)-c_{i}^{-\gamma_{1}}}{\gamma_{1} c_{i}^{-\gamma_{1}-1} z^{\prime}\left(m_{i}\right)^{2}+\gamma_{2} \gamma_{3}\left(m_{i}-\theta_{i}\right)^{-\gamma_{3}-1}} \times \frac{z^{\prime}\left(m_{i}\right)}{m_{i}}
$$

which is calculated for individual $i$.

The summary statistic of conditional distributions is provided in Table A5. The results show that on average a 1 per cent increase in the out-of-pocket rate will result in a 3.4 per cent reduction in medicine and paraclinical utilisation.

The test of moral hazard presence is conducted by Kolmogorov-Smirnov procedure. Table A6 indicates a significant difference between paired categories of conditional elasticity distribution, except these two pairs: (office workers, employer and employee) and (personal insurance, self-employed). On the basis of Table A5, the average of the elasticity for office workers and employer and employees is -5.4 and -5 , respectively. Although they had the best health status, they are subjected to moral hazard more intensively. The average of the elasticity of individuals in personal insurance and self-employed insurance is -4.4 and -4.1 respectively, which demonstrates a similarity of their attitudes toward medical care utilisation. In summary, the second hypothesis of our study, presence of moral hazard, is confirmed in all insurance categories. Mean of the elasticities are considerably different from those in the literature (reported mean of elasticities for uninsured by Bajari is -0.50 ), but the pattern of elasticity's magnitude, in comparison with the uninsured, is similar to Bajari. Uninsured are of the $(-2.64)$ and in the other insurance groups it is smaller. While our data reject the presence of moral hazard, Bajari finds evidences on the equality of elasticities' distribution between personal insured and uninsured.

Now we can determine the factors which affect the magnitude of the elasticity of medical expenditure with respect to a local change in the rate of reimbursement of medicine and paraclinical expenditures. An ad hoc model is specified to detect these effects. We use the elasticity of $i^{\text {th }}$ individual as dependent variable and insurance categories (dummy variables), age, household size, income, health group, Arrow-Pratt absolute risk aversion coefficient in medical utilisation and household out-of-pocket money as independent variables. Table A7 indicates that all variables significantly affect the elasticity (the moral hazard measure).

Office workers have the largest amount of moral hazard among others. Because, holding all of other factors fixed, their intercept is -4.1 , which is greater than those of 
employers and employee with -3.8 , self-employed -3.5 and personally insured with -3.1 per cent, respectively. Furthermore, a one-year increase in the age of insured people results in 0.006 unit increase in moral hazard. While the earnings of individuals increase, their moral hazard behaviour becomes crucial.

Table A7 figures out the findings. As it is depicted, higher income groups spend more on medical services. Reported health status by individuals influences strongly the moral hazard behaviour, such that individuals with poorer self-reported health status are subjected to more intensive moral hazard. The negative coefficient of risk aversion strengthens their tendency toward moral hazard behaviour. The highly significant and positive coefficient of household out-of-pocket money reinforces the presence of moral hazard. This positive sign reveals that any increases in out-of-pocket rate would result in considerable over-utilisation of medical care (moral hazard).

\section{Concluding remarks}

The propose of this paper is to provide an econometric assessment of Iranian households' attitudes toward health risk and test the presence of asymmetry information in the medical insurance market of Iran. The required data are taken from the household expenditure survey (2006) of Iran and the underlying model is based on the theoretical work of Cutler and Zeckhauser. ${ }^{7}$ We formulated a demand model of medical and paraclinical care in the presence of both adverse selection and moral hazard. More precisely, we made the following contribution in empirical work in Iran: (1) we developed a model with minimal parametric assumptions that allows for the effect of both adverse selection and moral hazard simultaneously in the demand for medicine and paraclinical care; (2) we used a non-parametric procedure for identification and estimation of a model that is not relied on ad hoc statistical assumption of the insurance selection process in the different insurance categories; (3) we quantified the level of moral hazard, and non-parametrically tested the presence of moral hazard between alternative health plans.

Our results confirm the presence of adverse selection hypothesis in personal health insurance and moral hazard in all health insurance categories (office workers, employer and employees, personally insured and self-employed insurance). Also, measured moral hazard test statistics reveal that the higher income earners are more subject to moral hazard behaviour. Furthermore, findings depict that individuals in our sample are more risk averse in medicine and paraclinical utilisation in comparison with the demand for other consumption goods. Also, the degree of risk aversion is higher among low-income individuals. Therefore, economic rescission may stimulate the demand for medical insurance through expanding the low-income population and exacerbating poverty. Individuals are sensitive to the reimbursement rate, therefore increases in the out-of-pocket rates and imposing different out-of-pocket plans, instead of the pooling plan of 30 per cent for all, for different insured groups may control moral hazard problems in over-utilisations of medical care. Adverse selection is more prevalent among self-employers and personally insured. The latter group of individuals is aged and needs more medical care, also a majority of them are socially categorised as low-income earners. Universal coverage in terms of basic social medical 
insurance is a major concern for the government and it aims to support their health with low insurance premiums; however they seem riskier insureds for the insurance organisation. Although our proposed semi-parametric method provides a more flexible and robust alternative for analysing the empirical aspects of adverse selection and moral hazard in health insurance, there is a limitation that our specified utility function is assumed to be separable in the consumption of the composite good and the difference between the medical utilisation and the latent health status.

\section{References}

Akerlof, G. (1970) 'The market for “Lemons”: Quality uncertainty and the market mechanism', Quarterly Journal of Economics 84(3): 488-500.

Arrow, K.J. (1963) 'Uncertainty and the welfare economics of medical care', American Economic Review 53(5): 941-973.

Bajari, P., Hong, H. and Khwaja, A. (2006) Moral hazard, adverse selection and health expenditures: A semiparametric analysis, NBER Working Paper no. 12445.

Bajari, P., Hong, H., Khwaja, A. and Marsh, C. (2009) 'Moral Hazard, Adverse Selection and Health Expenditure: A Semiparametric Analysis', http://www.econ.umn.edu/ bajari/research/hazard.pdf.

Blomqvist, A.G. (1997) 'Optimal non-linear health insurance', Journal of Health Economics 16(3): 303-321.

Briesacher, B. (2005) 'Medicare beneficiaries and the impact of gaining prescription drug coverage on inpatient and physician spending', Health Services Research 40[5 part1]: 1279-1296.

Browne, M.J. (1992) 'Evidence of adverse selection in the individual health insurance market', Journal of Risk and Insurance 59(1): 13-33.

Buchmueller, T.C. (2008) 'Community rating, entry-age rating and adverse selection in private health insurance in Australia', The Geneva Papers on Risk and Insurance -Issues and Practice 33(4): 588-609.

Cameron, A.C. (1988) 'A microeconometric model of the demand for health care and health insurance in Australia', The Review of Economic Studies 55: 85-106.

Cardon, J.H. and Hendel, I. (2001) 'Asymmetric information in health insurance: Evidence from the national medical expenditure survey', RAND Journal of Economics 32(3): 408-427.

Cave, J. (1985) 'Subsidy equilibrium and multiple-option insurance markets', in R. Scheffier and L.F. Rossiter (eds.) Advances in Health Economics and Health Services Research, Vol. 6, Greenwich, CT: JAI Press, 27-2.

Cherkin, D.C., Grothaus, L. and Wagner, E.H. (1989) 'The effect of office visit copayments on utilization in a health maintenance organization', Medical Care 27(7): 669-679.

Courbage, C. and De Coulon, A. (2004) 'Prevention and private health insurance in the U.K.', The Geneva Papers on Risk and Insurance-Issues and Practice 29(4): 719-727.

Cutler, D.M. and Reber, S.J. (1998) 'Paying for health insurance: The trade-off between competition and adverse selection', Quarterly Journal of Economics 113(2): 433-466.

Cutler, D.M. and Zeckhauser, R.J. (2000) 'The anatomy of health insurance', in A.J. Culyer and J.P. Newhouse (eds.) Handbook of Health Economics, Vol. 1A, Amsterdam, North-Holland: Elsevier, pp. 563-643.

Doerpinghaus, H.I. (1993) Asymmetric information and the demand for medigap insurance, working paper.

Feldman, R. and Dowd, D. (1991) 'Must adverse selection cause premium spirals?' Journal of Health Economics 10(3): 350-357.

Gilleskie, D.B. (1998) 'A dynamic stochastic model of medical care use and work absence', Econometrica 66(1): $1-45$.

Goldman, D. and Philipson, T.J. (2007) 'Integrated insurance design in the presence of multiple medical technologies', American Economic Review 97(2): 427-432.

Heaney, C.T. and Riedel, D.C. (1970) From Indemnity to Full Coverage: Changes in Hospital Utilization, Chicago: Blue Cross Association.

Keeler, E.B. and Rolph, J.E. (1988) 'The demand for episodes of treatment in the health insurance experiment', Journal of Health Economics 7(4): 337-367.

Kenkel, D.S. (2000) 'Prevention', in A.J. Culyer and J.P. Newhouse (eds.) Handbook of Health Economics, Vol. 1B, Elsevier: North Holland, pp. 1675-1720. 
596

Khan, N., Kaestner, R. and Lin, S.J. (2007) Prescription drug insurance and its effect on utilization and health of the elderly, National Bureau of Economic Research No 12848.

Khwaja, A.W. (2002) Health Insurance, Habits and Health Outcomes: Moral Hazard in a Dynamic Stochastic Model of Investment in Health, In: K.L. David and W. Zame (ed) Proceedings of the 2002. North American Summer Meetings of the Econometric Society: Labor Economics and Applied Econometrics.

Newey, W. and McFadden, D. (1994) 'Large sample estimation and hypothesis testing', in Handbook of Econometrics, Vol. 4, Chapter 36, Elsevier Science, pp. 2111-2245.

Pauly, M.V. (1968) 'The economics of moral hazard: Comment', American Economic Review 58(3): 531-537.

Pauly, M.V. (2006) Adverse Selection and Moral Hazard: Implications for Health Insurance Markets, Oberlin College Health Economics Conference, Oberlin, OH, 8-10 September.

Phelps, C.E. and Newhouse, J.P. (1974) 'Coinsurance, the price of time, and the demand for medical services', Review of Economics and Statistics 56: 334-342.

Roddy, P.C., Wallen, J. and Meyers, S.M. (1986) 'Cost sharing and use of health services: The United Mine Workers' of America Health Plan', Medical Care 24(9): 873-877.

Rothschild, M. and Stiglitz, J.E. (1976) 'Equilibrium in competitive insurance markets: An essay on the economics of imperfect information', Quarterly Journal of Economics 90(4): 629-649.

Rosett, R.N. and Huang, L-F. (1973) 'The effect of health insurance on the demand for medical care', Journal of Political Economy 81(2): 281-305.

Scitovsky, A.A. and Snyder, N.M. (1972) 'Effect of coinsurance on use of physician services', Social Security Bulletin 35(6): 3-19.

Shang, B. (2005) 'The cost and health effects of prescription drug coverage and utilization in the Medicare population. Dissertation Research for the Pardee Rand Graduate School from http://www.rand.org/pubs/ rgs_dissertation/2005/RAND_RGSD197.pdf.

Smirnov, N. (1939) 'On the estimation of the discrepancy between empirical curves of distribution for two independent samples', Bulletin Mathématique de I'Université de Moscou 2: 3-14.

Spence, M. and Zeckhauser, R. (1971) 'Insurance, information, and individual action', American Economic Review 61(2): 380-387.

Stanciole, A.E. (2008) 'Health insurance and lifestyle choices: Identifying ex ante moral hazard in the US market', The Geneva Papers on Risk and Insurance - Issues and Practice 33(4): 627-644.

Stuart, B., Doshi, J.A., Briesacher, B., Wrobel, M.V. and Baysac, F. (2004) 'Impact of prescription coverage on hospital and physician costs: A case study of Medicare beneficiaries with chronic obstructive pulmonary disease', Clinical Therapeutics 26(10): 1688-1699.

Wilson, C.H. (1980) 'The nature of equilibrium in markets with adverse selection', The Bell Journal of Economics 11(1): 108-130.

Zeckhauser, R. (1970) 'Medical insurance: A case study of the tradeoff between risk spreading and appropriate incentives', Journal of Economic Theory 2(1): 10-26.

Zweifel, P. and Breyer, F. (1997) Health Economics, New York: Oxford University Press.

\section{About the Author}

GholamReza Keshavarz Haddad has a PhD in Economics (2000), University of Tehran, Iran. Currently he is an Associate Professor in Graduate School of Management and Economics, Sharif University of Technology and teaches Microeconomics and Econometrics in the school. His main field of research is financial economics, but does researches in labor economics too. He has published 25 papers in Iranian local academic journals, and two papers in the international ISI journals.

Mahdieh Zomoroodi got her Bachelor of Science in Applied Mathematics from the Department of Mathematics and her Master of Science in Economics from the Graduate School of Management and Economics of Sharif University and Technology in 2008. Now, She is on the job market and is looking for a job opportunity. 


\section{Appendix}

See Tables A1-A8.

Table A1 Estimation of risk aversion parameters

\begin{tabular}{lcc}
\hline & Generalised method of moment estimations & \\
\hline$\gamma_{1}$ & $\gamma_{2}$ & $\gamma_{3}$ \\
\hline 0.269183 & 39.50315 & 0.708999 \\
$(2.231314)$ & $(2.236507)$ & $(4.652373)$ \\
$R^{2}$ & & \\
$J$-statistic & 0.047652 & \\
\hline
\end{tabular}

The $t$-statistics are reported in parenthesis.

Table A2 Summary statistics for risk aversion in medicine and paraclinical care by income group

\begin{tabular}{lccccc}
\hline Variable & Observation & Mean & Std. dev. & Min & Max \\
\hline Riskavers_m0 & 3086 & 0.0000211 & $7.53 \mathrm{e}-06$ & $1.66 \mathrm{e}-06$ & 0.0000792 \\
Riskavers_m1 & 3090 & 0.0000162 & $5.63 \mathrm{e}-06$ & $1.41 \mathrm{e}-06$ & 0.0000323 \\
Riskavers_m2 & 3090 & 0.000014 & $6.09 \mathrm{e}-06$ & $1.28 \mathrm{e}-06$ & 0.0000402 \\
Riskavers_m3 & 3092 & 0.0000123 & $6.32 \mathrm{e}-06$ & $1.22 \mathrm{e}-06$ & 0.0000326 \\
Riskavers_m4 & 3092 & 0.0000107 & $6.36 \mathrm{e}-06$ & $8.51 \mathrm{e}-07$ & 0.000034 \\
Riskavers_m5 & 3090 & $9.78 \mathrm{e}-06$ & $6.21 \mathrm{e}-06$ & $1.05 \mathrm{e}-06$ & 0.0000262 \\
Riskavers_m6 & 3092 & $8.26 \mathrm{e}-06$ & $5.96 \mathrm{e}-06$ & $9.46 \mathrm{e}-07$ & 0.0000285 \\
Riskavers_m7 & 3089 & $7.02 \mathrm{e}-06$ & $5.48 \mathrm{e}-06$ & $8.78 \mathrm{e}-07$ & 0.0000248 \\
Riskavers_m8 & 3091 & $6.03 \mathrm{e}-06$ & $5.08 \mathrm{e}-06$ & $8.22 \mathrm{e}-07$ & 0.0000259 \\
Riskavers_m9 & 3090 & $5.37 \mathrm{e}-06$ & $4058 \mathrm{e}-06$ & $6.87 \mathrm{e}-07$ & 0.0000269 \\
\hline
\end{tabular}

Table A3 Kolmogorov-Smirnov test for equality of distribution of latent health shocks

\begin{tabular}{lccrr}
\hline Insurance category & 2 & 3 & 4 & 5 \\
\hline 1 & 0.7518 & 0.7226 & 0.6606 & 0.6735 \\
& $(0.000)$ & $(0.000)$ & $(0.000)$ & $(0.000)$ \\
2 & & 0.1526 & 0.1861 & 0.1594 \\
& & $(0.000)$ & $(0.000)$ & $0.000)$ \\
3 & & & $(0.090)$ & $(0.0643$ \\
& & & & $0.000)$ \\
4 & & & $(0.108)$ \\
\hline
\end{tabular}

The combined Kolmogorov-Smirnov statistic is reported with corrected $p$-value in parenthesis, individuals are categorised as: 1 uninsured, 2 office workers, 3 employee and employer, 4 personally insured and 5 selfemployed. 
Table A4 Summary statistics for recovered health shocks by insurance category (in US\$)

\begin{tabular}{|c|c|c|c|c|c|}
\hline Variable & Observation & Mean & Std. dev. & Min & $\operatorname{Max}$ \\
\hline All insurance categories & 30902 & $-1.142 \mathrm{e}-08$ & 60.42563 & -104.76 & 4435.047 \\
\hline Uninsured & 20375 & 2.27913902 & 23.02663 & -17.094 & 1626.545 \\
\hline Office worker & 3935 & -7.4927055 & 113.8845 & -104.18 & 4435.047 \\
\hline Employer provided & 4002 & -6.3088245 & 80.70462 & -77.781 & 1995.229 \\
\hline Personally purchased & 1063 & 5.85628063 & 99.39252 & -90.388 & 1344.611 \\
\hline Self-employed & 1527 & 1.35495988 & 95.52837 & -104.76 & 1322.923 \\
\hline
\end{tabular}

Table A5 Summary statistics for elasticity of medicine and paraclinical expenditure with respect to the effective price of medicine and paraclinical expenditure by insurance category

\begin{tabular}{lccccc}
\hline Variable & Observation & Mean & Std. dev & Min & Max \\
\hline All insurance categories & 19,794 & -3.441077 & 6.135718 & -157.1703 & -0.015513 \\
No insurance & 12,908 & -2.641438 & 4.316326 & -93.88652 & -0.015513 \\
Office worker & 2520 & -5.374973 & 8.826699 & -120.7303 & -0.0195767 \\
Employer provided & 2596 & -4.978761 & 8.514157 & -140.3197 & -0.0350302 \\
Personally purchased & 747 & -4.423687 & 8.48941 & -157.1703 & -0.0397845 \\
Self-employed & 1023 & -4.147308 & 6.372234 & -70.85225 & -0.0456159
\end{tabular}

Elasticity of medicine and paraclinical expenditure with respect to the effective price of medicine and paraclinical expenditure which is calculated as:

$$
\text { elasticity }=\frac{\partial m_{i}}{\partial z^{\prime}\left(m_{i}\right)} \times \frac{z^{\prime}\left(m_{i}\right)}{m_{i}}=\frac{-\gamma_{1} c_{i}^{-\gamma_{1}-1} m_{i} z^{\prime}\left(m_{i}\right)-c_{i}^{-\gamma_{1}}}{\gamma_{1} c_{i}^{-\gamma_{1}-1} z^{\prime}\left(m_{i}\right)^{2}+\gamma_{2} \gamma_{3}\left(m_{i}-\theta_{i}\right)^{-\gamma_{3}-1}} \times \frac{z^{\prime}\left(m_{i}\right)}{m_{i}} .
$$

Table A6 Kolmogorov-Smirnov test for equality of distribution of price elasticity

\begin{tabular}{|c|c|c|c|c|}
\hline Insurance category & 2 & 3 & 4 & 5 \\
\hline 1 & $\begin{array}{c}0.2456 \\
(0.000)\end{array}$ & $\begin{array}{c}0.2193 \\
(0.000)\end{array}$ & $\begin{array}{c}0.1594 \\
(0.000)\end{array}$ & $\begin{array}{c}0.1636 \\
(0.000)\end{array}$ \\
\hline 2 & & $\begin{array}{c}0.0356 \\
(0.079)\end{array}$ & $\begin{array}{c}0.1014 \\
(0.000)\end{array}$ & $\begin{array}{c}0.0922 \\
(0.000)\end{array}$ \\
\hline 3 & & & $\begin{array}{c}0.0793 \\
(0.001)\end{array}$ & $\begin{array}{r}0.0672 \\
(0.003)\end{array}$ \\
\hline 4 & & & & $\begin{array}{c}0.0465 \\
(0.307)\end{array}$ \\
\hline
\end{tabular}

The combined Kolmogorov-Smirnov statistic is reported with corrected $p$-value in parenthesis, individuals are categorised as: 1 uninsured, 2 office workers, 3 employee and employer, 4 personally insured and 5 selfemployed. 
Table A7 OLS results from elasticity regression

\begin{tabular}{lcccc}
\hline Elasticity & Coefficient & Std. err. & t statistic & Probability \\
\hline Dumins2 & -4.117747 & 0.156551 & -26.30287 & 0.0000 \\
Dumins3 & -3.790155 & 0.151317 & -25.04785 & 0.0000 \\
Dumins4 & -3.549039 & 0.251119 & -14.13291 & 0.0000 \\
Dumins5 & -3.115444 & 0.218789 & -14.23950 & 0.0000 \\
Age & -0.005868 & 0.002633 & -2.228275 & 0.0259 \\
Hsize & -0.189418 & 0.018332 & -10.33281 & 0.0000 \\
Inc & $-9.69 \mathrm{e}-08$ & $1.04 \mathrm{e}-08$ & -9.318779 & 0.0000 \\
Healthgroup & -7.387721 & 0.453164 & -16.30255 & 0.0000 \\
Riskaverse_m & -110509.7 & 8271.539 & -13.36024 & 0.0000 \\
Hoop & $6.15 \mathrm{e}-06$ & $1.99 \mathrm{e}-07$ & 30.87976 & 0.0000
\end{tabular}

$R^{2}=0.072467$

Dumins $i=$ Dummy variable of insurance category i, Age $=$ Husbandman age, Hsize $=$ Household size, Inc $=$ Income, Healthgroup $=$ Reported health situation, Riskaverse_ $m=$ Arrow-Pratt absolute risk aversion coefficient in medicine and paraclinical utilisation, Hoop $=$ Household out of pocket money.

Table A8 Summary statistics for elasticity of medicine and paraclinical expenditure with respect to the effective price of medicine and paraclinical expenditure by income group.

\begin{tabular}{lccccc}
\hline Variable & Observation & Mean & Std. dev. & Min & Max \\
\hline Elasticity_0 & 1780 & -2.503238 & 4.898899 & -93.88652 & -0.0471497 \\
Elasticity_1 & 1926 & -2.812626 & 4.913943 & -76.46654 & -0.0448911 \\
Elasticity_2 & 1978 & -2.899937 & 4.325026 & -52.57258 & -0.0155513 \\
Elasticity_3 & 1978 & -3.110082 & 5.106268 & -70.85225 & -0.0340935 \\
Elasticity_4 & 1980 & -3.251924 & 5.689873 & -140.3197 & -0.0448965 \\
Elasticity_5 & 1991 & -3.494347 & 5.376084 & -69.49345 & -0.0231215 \\
Elasticity_6 & 2051 & -3.733157 & 6.63185 & -106.3919 & -0.0439826 \\
Elasticity_7 & 2026 & -4.129372 & 7.024086 & -74.96173 & -0.0258574 \\
Elasticity_8 & 2019 & -3.998699 & 6.991335 & -120.7303 & -0.0360248 \\
Elasticity_9 & 2065 & -4.290425 & 8.544698 & -157.1703 & -0.0195767 \\
\hline
\end{tabular}

